\title{
Vaccination Status and Attitude towards HPV vaccination among Private University Students uncovered under the National HPV immunization Programme, 2010 in Malaysia
}

\begin{abstract}
Purpose: In 2010, MOH, Malaysia initiated national HPV immunization programme to all girls aged 13 years and in 2018, extended free/subsidised HPV vaccination to all unmarried women born between1990-1996, yet little is known about the vaccination status and the attitude for acceptance of this vaccine.

Methods: A cross-sectional study among private university students was conducted in Kedah state, Malaysia. The primary outcome measure was to estimate the HPV vaccination status among the study population. The secondary outcome was to assess their attitude and perception towards HPV vaccination and predict socio-demographic factors which favour HPV vaccination.

Results: The overall response rate was $77 \%(\mathrm{~N}=696)$. About $55 \%$ of the respondents reported to have received at least one HPV injection. However, their attitude and perception towards HPV infection and HPV vaccination was neutral. Nearly half of the unvaccinated respondents $(46 \%)$ were intended to get vaccinated. Half of them were aware of the nation immunization program and $52 \%$ of them were aware that $\mathrm{MOH}$ is providing free / subsidized HPV vaccination to all unmarried women born between 1990 and 1996. The statistically significant $(p<.05)$ socio-demographic factors predictive for vaccination were education $(p=.033)$ and year of study $(p=.005)$

Conclusion: Despite more than half of the respondents were vaccinated, still many of the respondents has not yet received the vaccine. A comprehensive and sustainable HPV and cervical cancer education should be incorporated into health education at schools from the early teen-ages in order to achieve the desired impact, which is to limit the spread of HPV infection, thus decreasing the risk for cervical cancer incidence and mortality.
\end{abstract}

Keywords: attitude, human papillomavirus (HPV) infection, perception, vaccination status
Volume I Issue 6 - 2018

\author{
Abdul Nazer Ali,' Wong Sue Fern,' Sunil K \\ Prajapati,' Nazer Zulfikar Ahmed ${ }^{2}$ \\ 'Faculty of pharmacy, AIMST University, Malaysia \\ ${ }^{2}$ Cognizant Technology Solutions India Private Limited, India
}

Correspondence: Abdul Nazer Ali, Faculty of Pharmacy, AIMST University, Semeling, 08100 Bedong, Kedah Darul Aman, Malaysia,Email abdul.nazaralil6@gmail.com

Received: November 05, 2018 | Published: December 03, 2018

\section{Introduction}

Human Papilloma Virus (HPV), the most common sexually transmitted infection (STI) is commonly seen in adolescents or young adults. ${ }^{1}$ More than $50 \%$ of sexually active men and women have a higher chance of getting HPV genotypes causing anogenital, head \& neck or cervical cancers during their lifetime. ${ }^{2,3}$ HPV type-16 and 18 are responsible for $70 \%$ of all cervical cancer and type- 6 and 11 for genital warts, worldwide and 14- 20 years are the age when HPV infects most women. ${ }^{4,5}$ According to the Centres for Disease Control and Prevention (CDC), all genders should get vaccinated as early as 11 or 12 years and those not vaccinated, are encouraged to get vaccinated before 26 years in women and 21 years for males. ${ }^{6}$ Many investigations have reported a tremendous lack of knowledge about HPV infection despite its increased prevalence and possible consequences. ${ }^{7-9}$ The primary objective of this study was to estimate the HPV vaccination status and their attitudes and perception towards vaccination among the unvaccinated young adults aged 20 to 26 years in Kedah state, Malaysia. The study findings could provide the health care system with a better understanding on the status of HPV vaccination in this vulnerable population and formulate appropriate approaches to address the national demon.

\section{Outcome measures}

The primary outcome was to estimate the HPV vaccination status among the study population. The secondary outcome was to assess their attitude \& perception (A\&P) towards HPV vaccination and predict socio-demographic factors which favour HPV vaccination.

\section{Method}

\section{Study design, site, target population and time}

A cross-sectional study using convenient sampling was conducted among students aged 18-26 years and age eligible for HPV vaccination from various faculties of a private university, Kedah state, Malaysia. The survey was conducted between March and May, 2018 for a period of three months.

\section{Inclusion and exclusion criteria}

The inclusion criteria included students from various faculties aged 18-26 years from both genders willing to participate and signed informed consent form. Those involved in pilot study, not willing to participate in the study, incomplete survey forms and ages $<18$ or $>26$ years were excluded. 


\section{Recruitment of study population}

The study participants were identified based on vaccination eligibility age. Adequate information regarding the study objectives was explained and assurance for anonymous and strict confidentiality of data collected was assured followed by informed consent form and formal request for their time and cooperation for completing the survey questionnaire.

\section{Modality of obtaining response}

A pre-validated, structured questionnaire was distributed in the classroom setting, and the completed questionnaires were collected back. About 15 minutes was taken for completion of the questionnaire.

\section{Sample size calculation}

The sample size was calculated using an automated software programme, Raosoft sample size calculator which used Cohen's statistical power analysis method. ${ }^{10-12}$ The estimated sample size was based on total students enrolled in the University $(\mathrm{N}=3000)$, was calculated at $95 \% \mathrm{CI}, 5 \%$ margin of error with $50 \%$ response distribution and the sample size required was 341 . A $20 \%$ margin for drop-outs (68) was added and the sample size was further rounded off $(\mathrm{N}=400)$ to overcome errors and increase the reliability of the results.

\section{Development of the questionnaires ${ }^{13}$}

The study instrument (questionnaire) was adapted from other published studies and modified to meet the objective of this study. The attitude \& perception (A\&P) section measured the current beliefs, misconceptions and attitudes among the study population about HPV infection and HPV vaccination. This was effectively designed using a five-point Likert scale like strongly disagree, disagree, not sure, agree and strongly agree to mark their best agreement to the A\&P testing statements which covered: Health seeking behaviour; importance and follow-up procedure of HPV prevention; importance, significance, and severity of HPV infection and vaccination; importance of vaccination referral; cost, affordability, willingness for HPV vaccination and HPV acceptance. The questionnaire contained 15 statements on A\&P testing domain. One point for "negative attitude statements" and five points for "positive attitude statements" were allotted for scoring patterns with possible scores of 15 to $75 . .^{14-16}$

\section{Validation of the questionnaire ${ }^{13}$}

The final questionnaire was content validated among two practising physicians from community medicine and five academicians from clinical pharmacy and pharmacy practice unit, AIMST University, Kedah state, Malaysia and face validated by $(\mathrm{N}=30)$ potential respondents. The participants were encouraged to ask questions for any doubt or confusing items. Such items were explained by researcher in a more understandable manner and noted for later adjustment. Once completed, the results were analysed to validate the degree of understanding within a group. The questions were modified wherever necessary to reflect the pre-testing results. Thus, the final version of the questionnaire was arrived. A pilot study was conducted using Cronbach's alpha coefficient for internal consistency and the alpha value of final questionnaire was found to be .811 . Going by the rule of George and Mallery, the reliability coefficient was found to be $\operatorname{good}(>.8) \cdot{ }^{17,18}$

\section{Grading cut-off scores}

Based on the original Bloom's cut off points, assessment with a score of $80-100 \%$ correct response refers a good score, $60-79 \%$ as satisfactory, average or moderate and a score less than $60 \%$ correct response as poor. ${ }^{19,20}$

\section{Ethical considerations}

The research proposal along with the study instrument and informed consent form (ICF) was submitted to the Institutional Review Board (IRB), AIMST University Human Ethical Committee (AUHEC) and the ethical clearance was obtained. ICF was obtained from each participant before the distribution of survey forms.

\section{Statistical analyses of data}

The analysis was performed using IBM SPSS Statistics for Windows (Version 23. Armonk, NY: IBM Corp.). Descriptive statistics for frequency and percentage was computed for categorical variables. Numerical data, not normally distributed were presented as median and interquartile range (IQR). The inferential statistics was done using Spearman's rho correlation. Further, an attempt to identify the predictive factors among the dependent variables using linear regression was done. The significance level was set at .05 for all statistical tests. All percentage is displayed in the text or in parentheses with no decimal places as per APA reporting guideline recommendation.

\section{Results}

\section{Response rate}

Among 900 survey forms distributed, 696 completed survey forms were retrieved with an overall response rate of $77 \%$. The drop-outs were mainly due to incomplete questionnaires, non-retrievable survey forms or unwilling to participate.

\section{Socio-demographic characteristics of the study population}

Table 1 depicts the respondents' socio-demographic characteristics among the study population.

Table I Socio-demographic characteristics $(N=696)$

\begin{tabular}{lll}
\hline Variables & N & $\%$ \\
\hline Age in Years & & \\
$18-20$ & 285 & 41 \\
$21-23$ & 368 & 53 \\
$24-26$ & 43 & 6 \\
Gender & & \\
Male & 170 & 24 \\
Female & 526 & 76 \\
Race & & \\
Malay & 19 & 2 \\
Chinese & 544 & 79 \\
Indian & 133 & 19 \\
Location & & \\
\hline
\end{tabular}




\begin{tabular}{lcc} 
Table Continued & N & $\%$ \\
\hline Variables & 158 & 23 \\
\hline Rural & 538 & 77 \\
Urban & & \\
Education & 143 & 21 \\
Foundation & 59 & 8 \\
Diploma & 494 & 71 \\
Degree & & \\
Course of Study & 143 & 21 \\
Foundation studies & 141 & 20 \\
Diploma in Nursing \& Physiotherapy & 251 & 36 \\
Pharmacy & 117 & 17 \\
Dentistry & 37 & 5 \\
MBBS & 7 & 1 \\
Engineering \& Business & & \\
Year of Study & 287 & 41 \\
Year I & 126 & 18 \\
Year 2 & 170 & 25 \\
Year 3 & 93 & 13 \\
Year 4 & 20 & 3 \\
Year 5 & & \\
\hline
\end{tabular}

\section{Response of HPV vaccinated respondents}

Out of the 696 respondents, 379 (54\%) were HPV vaccinated of which, $78 \%$ respondents were vaccinated with all 3 doses, whereas, $9 \%$ and $13 \%$ were either 1 or 2 dose(s) vaccinated. The place of vaccination was mostly in secondary schools $(56 \%)$, under the $\mathrm{MOH}$ national vaccination program during their Form 1 study. Whereas, $37 \%$ of them were vaccinated in clinics / hospitals, while $7 \%$ were not sure about their place of vaccination. Nearly $93 \%$ were vaccinated for free, while only $7 \%$ have paid for their vaccination $(p<.001)$ (Table 2).

Table 2 Response of the HPV vaccinated respondents

\begin{tabular}{|c|c|c|c|}
\hline S. No. & Variables / items $(\mathbf{N}=\mathbf{3 7 9})$ & $\mathbf{N}(\%)$ & *p-value \\
\hline \multirow{4}{*}{ I } & Number of doses & & \multirow{4}{*}{$<.001$} \\
\hline & I dose & $36(9)$ & \\
\hline & 2 doses & $48(13)$ & \\
\hline & 3 doses & $295(78)$ & \\
\hline \multirow{4}{*}{2} & Place of vaccination & & \multirow{4}{*}{$<.001$} \\
\hline & $\begin{array}{l}\text { Under secondary schools' } \\
\text { vaccination program during Form I }\end{array}$ & $211(56)$ & \\
\hline & Clinics / hospitals & $139(37)$ & \\
\hline & Not sure & $29(7)$ & \\
\hline \multirow{3}{*}{3} & Did you pay for the vaccination? & & \multirow{3}{*}{$<.001$} \\
\hline & Yes & $26(7)$ & \\
\hline & No & $353(93)$ & \\
\hline
\end{tabular}

*Chi Square Test ( $p<.05$ is considered statistically significant).

\section{Response of unvaccinated respondents}

Table 3 depicts the response of the unvaccinated respondents $(\mathrm{N}=317)$. Nearly half $(46 \%)$ of the unvaccinated respondents were intended to get vaccinated. About $17 \%$ and $37 \%$, either didn't want to get vaccinated or were not sure of getting vaccinated. Those who were willing to get vaccinated would either get vaccinated in 3 to 6 months $(42 \%)$ or within a year $(56 \%)$. Only $2 \%$ did not want to get vaccinated at all.

Table 3 Response of the unvaccinated respondents

\begin{tabular}{|c|c|c|c|}
\hline $\begin{array}{l}\text { S. } \\
\text { No. }\end{array}$ & $\begin{array}{l}\text { Variables / items }(\mathbf{N}= \\
3 \mid 7)\end{array}$ & $\mathbf{N}(\%)$ & *p-value \\
\hline \multirow{4}{*}{$\mathbf{I}$} & \multicolumn{3}{|c|}{ Are you intended to get vaccinated? } \\
\hline & Yes & $147(46)$ & \multirow{3}{*}{$<.001$} \\
\hline & No & $54(17)$ & \\
\hline & Don't know & $116(37)$ & \\
\hline \multirow{4}{*}{2} & \multicolumn{3}{|c|}{ When would you like to get vaccinated? $(n=\mid 47)$} \\
\hline & 3 to 6 months & $62(42)$ & \multirow{3}{*}{0.037} \\
\hline & Within I year & $82(56)$ & \\
\hline & Not at all & $3(2)$ & \\
\hline \multirow{3}{*}{3} & \multicolumn{3}{|c|}{$\begin{array}{l}\text { Are you aware that the Ministry of Health, Malaysia } \\
\text { is giving immunization to all girls aged } 13 \text { years since } \\
2010 \text { ? }\end{array}$} \\
\hline & Yes & $158(50)$ & \multirow[t]{2}{*}{$<.001$} \\
\hline & No & $159(50)$ & \\
\hline \multirow{3}{*}{4} & \multicolumn{3}{|c|}{$\begin{array}{l}\text { Are you aware that the Malaysia Health Ministry } \\
\text { is giving free / subsidized HPV vaccination to all } \\
\text { unmarried women born between } 1990 \text { and } 1996 ?\end{array}$} \\
\hline & Yes & $165(52)$ & $<.001$ \\
\hline & No & $152(48)$ & \\
\hline
\end{tabular}

*Chi Square Test ( $p<.05$ is considered statistically significant).

Half of the unvaccinated respondents $(50 \%)$ were aware of the national immunization program whereas, the other half were not aware of the information. Nearly $52 \%$ of them were also aware that, the MOH is providing free / subsidized HPV vaccination to all unmarried women born between the year 1990 and $1996(p<.05)$.

\section{Attitude \& perception of the respondents towards HPV infection \& HPV vaccination}

A total of 15 attitude \& perception based statements using 'fivepoint Likert scale' from 'strongly disagree to strongly agree were accessed and the score was arrived by summing up the responses for all 15 statements, the minimum possible score was 15 and the maximum score was 75 . The responses to the $15 \mathrm{~A} \& \mathrm{P}$ items is summarised in Table 4.

Among the 15 A\&P-based statements, 'Sex education is a must for school and university students', 'Those with multiple sex partners will be at higher risk for HPV infection' and 'Education and awareness campaigns regarding complications of infection will encourage HPV vaccination' had the maximum percentage score for positive attitude $(92 \%, 81 \%$ and $90 \%)$, whereas, 'HPV vaccination may indirectly 
cause people to have indiscriminate casual sex frequently' had the highest percentage score for negative attitude (18\%). The A\&P score distribution of the respondents was mostly at neutral. Most of the respondents showed significant $(p<.05)$ neutral to positive attitude $\&$ perception towards the statements. The median (IQR) A\&P scores were 59 (9) ranging from 19 to 75.

\section{Correlation between A\&T and KAP scores}

The Spearman's rank-order correlation test between total attitude $\&$ perception score and total KAP score showed a significantly strong, positive correlation. The correlation of median A\&P score 59 (9) to median KAP score, 68 (10) was strong positively correlated and found to be $\left[\mathrm{r}_{\mathrm{s}}(696)=.925, p<.001\right]$.

\section{Analysis for predictor variables using linear regression}

The analysis for predictor variables is shown in Table 5 .

The socio-demographic variables like education and year of study were the only two factors that showed statistical significance $(p<.05)$. The odds ratio and $95 \%$ confidence interval of education and year of study regarding HPV infection \& HPV vaccination are depicted in Table $5(\mathrm{~N}=696)$. The regression test for education was $[\mathrm{t}(10)=2.14$, $p=.033]$ whereas the year of study was $[\mathrm{t}(10)=2.85, p=.005]$. The respondents with higher education and year of study were more likely to be more knowledgeable about HPV infection \& HPV vaccination. Therefore, higher the education or year of study, the better was their attitude \& perception towards vaccination acceptance.

Table 4 Proportion of correct responses towards A\&P items

\begin{tabular}{|c|c|c|c|c|c|c|c|}
\hline $\begin{array}{l}\text { AP. } \\
\text { No. }\end{array}$ & Attitude \& perception items & $\begin{array}{l}\text { SD } \\
\mathbf{N} \\
(\%)\end{array}$ & $\begin{array}{l}\text { D } \\
\text { N (\%) }\end{array}$ & $\begin{array}{l}\mathbf{N} \\
\mathbf{N}(\%)\end{array}$ & $\begin{array}{l}\text { A } \\
\mathbf{N}(\%)\end{array}$ & $\begin{array}{l}\text { SA } \\
\text { N (\%) }\end{array}$ & *p-Value \\
\hline I & $\begin{array}{l}\text { Sexually active individuals are at risk of contracting HPV } \\
\text { infection. }\end{array}$ & $\begin{array}{l}5 \\
(1)\end{array}$ & $\begin{array}{l}14 \\
(2)\end{array}$ & $\begin{array}{l}152 \\
(22)\end{array}$ & $\begin{array}{l}330 \\
(47)\end{array}$ & $\begin{array}{l}195 \\
(28)\end{array}$ & $<.001$ \\
\hline 2 & Sex education is a must for school and university students. & $\begin{array}{l}13 \\
(2)\end{array}$ & $\begin{array}{l}9 \\
\text { (I) }\end{array}$ & $\begin{array}{l}34 \\
(5)\end{array}$ & $\begin{array}{l}275 \\
(40)\end{array}$ & $\begin{array}{l}365 \\
(52)\end{array}$ & $<.001$ \\
\hline 3 & $\begin{array}{l}\text { Those with multiple sex partners will be at higher risk for HPV } \\
\text { infection. }\end{array}$ & 6 & 10 & $\begin{array}{l}116 \\
(17)\end{array}$ & $\begin{array}{l}261 \\
(37)\end{array}$ & $\begin{array}{l}303 \\
(44)\end{array}$ & $<.001$ \\
\hline 4 & Unsafe sex could cause HPV infection. & 4 & $\begin{array}{l}16 \\
(2)\end{array}$ & $\begin{array}{l}139 \\
(20)\end{array}$ & $\begin{array}{l}281 \\
(40)\end{array}$ & $\begin{array}{l}256 \\
(37)\end{array}$ & $<.001$ \\
\hline 5 & $\begin{array}{l}\text { Those with a family history of HPV infection are at high risk of } \\
\text { contracting cervical cancer. }\end{array}$ & 9 & 43 & $\begin{array}{l}267 \\
(39)\end{array}$ & $\begin{array}{l}246 \\
(35)\end{array}$ & $\begin{array}{l}131 \\
(19)\end{array}$ & $<.001$ \\
\hline 6 & Using condoms can reduce HPV infection. & 6 & 45 & $\begin{array}{l}276 \\
(40)\end{array}$ & $\begin{array}{l}250 \\
(36)\end{array}$ & $\begin{array}{l}119 \\
(17)\end{array}$ & $<.001$ \\
\hline 7 & $\begin{array}{l}\text { Pap smear is one of the effective methods to detect cervical } \\
\text { cancer. }\end{array}$ & $\begin{array}{l}7 \\
(1)\end{array}$ & $\begin{array}{l}4 \\
\text { (I) }\end{array}$ & $\begin{array}{l}195 \\
(28)\end{array}$ & $\begin{array}{l}319 \\
(46)\end{array}$ & $\begin{array}{l}|7| \\
(24)\end{array}$ & $<.001$ \\
\hline 8 & $\begin{array}{l}\text { If sexually active, a female should consider undergoing Pap } \\
\text { smear test. }\end{array}$ & $\begin{array}{l}3 \\
0\end{array}$ & $\begin{array}{l}15 \\
\text { (2) }\end{array}$ & $\begin{array}{l}147 \\
(21)\end{array}$ & $\begin{array}{l}326 \\
(47)\end{array}$ & $\begin{array}{l}205 \\
(30)\end{array}$ & $<.001$ \\
\hline 9 & A complete course of HPV vaccination is mandatory. & $\begin{array}{l}9 \\
\text { (I) }\end{array}$ & $\begin{array}{l}\text { II } \\
\text { (I) }\end{array}$ & $\begin{array}{l}128 \\
(19)\end{array}$ & $\begin{array}{l}264 \\
(38)\end{array}$ & $\begin{array}{l}284 \\
(4 I)\end{array}$ & $<.001$ \\
\hline 10 & HPV is not sexually transmitted. & $\begin{array}{l}7 \\
\text { (I) }\end{array}$ & $\begin{array}{l}17 \\
\text { (2) }\end{array}$ & $\begin{array}{l}129 \\
(19)\end{array}$ & $\begin{array}{l}293 \\
(42)\end{array}$ & $\begin{array}{l}250 \\
(36)\end{array}$ & $<.001$ \\
\hline II & $\begin{array}{l}\text { HPV vaccination is recommended even if you are needed to } \\
\text { pay for it. }\end{array}$ & $\begin{array}{l}10 \\
\text { (I) }\end{array}$ & $\begin{array}{l}22 \\
-3\end{array}$ & $\begin{array}{l}109 \\
(16)\end{array}$ & $\begin{array}{l}310 \\
(45)\end{array}$ & $\begin{array}{l}245 \\
(35)\end{array}$ & $<.001$ \\
\hline
\end{tabular}


Education and awareness campaigns regarding complications of infection will encourage HPV vaccination.

HPV vaccination may indirectly cause people to have indiscriminate casual sex frequently.

HPV vaccination can decrease healthcare costs in the long run.

99

(I)

107

(I5)

57

57

(8)

(3)

$$
\text { I I }
$$

15

\begin{abstract}
Cervical cancer ranks as the second leading cause of female
cancer in Malaysia.
Cervical cancer ranks as the second leading cause of female
cancer in Malaysia.
\end{abstract}

(1)

$\begin{array}{lll}306 & 315 & \\ (44) & (46) & <.001 \\ & & \\ 160 & 73(11) & <.001 \\ (23) & & \\ & & \\ 296 & 149 & \\ (43) & (21) & <.001 \\ & & \\ 240 & 131 & \\ (34) & (19) & <.001\end{array}$

*Chi Square Test, $\mathrm{p}<.05$ is statistically significant, $\mathrm{AP}=$ Attitude $/$ Perception; $\mathrm{SA}=$ Strongly

Disagree, $D=$ Disagree, $N=$ Neutral, $A=$ Agree and $S A=$ Strongly Agree

Table 5 Linear Regression Analysis for the Predictor Variables

\begin{tabular}{|c|c|c|c|c|c|c|}
\hline \multirow{2}{*}{ Variable } & \multicolumn{2}{|c|}{ Un standardized coefficient } & \multirow{2}{*}{$\begin{array}{l}\text { Standardized coefficient } \\
\text { Beta }\end{array}$} & \multirow{2}{*}{ Odd ratio } & \multirow{2}{*}{$95 \% \mathrm{Cl}$} & \multirow{2}{*}{ p-value } \\
\hline & B & Standard error & & & & \\
\hline Education & 0.072 & 0.034 & 0.103 & 2.14 & $.006-.138$ & $.033^{*}$ \\
\hline Year of Study & 0.075 & 0.026 & 0.157 & 2.85 & $.023-.126$ & $.005^{*}$ \\
\hline
\end{tabular}

*Linear regression, $\mathrm{p}<.05$ is statistically significant

\section{Discussion}

\section{Development and validation of the questionnaire}

This study questionnaire was developed and validated to measure the HPV vaccination status and A\&P towards HPV vaccination. The questionnaire covered a wide range of issues relating to HPV infection \& HPV vaccination. The efficacy of questionnaire was established through various stages including pilot tests among the study population. The interviewee feedback for the questionnaire revealed, most of the respondents neither had difficulty nor confusion, embarrassing or displeasing contents with any of the questions / statements regarding HPV used for pilot testing. The participants completed the questionnaire within 15 minutes. This study was very carefully designed not to touch any sensitive issues or sexuality as it is still tabooed and reluctant to talk about sexual lifestyle in Malaysia. ${ }^{21}$ The construct analysis of the questionnaire confirmed reliability with Cronbach's alpha value of $.811 .^{22-24}$

\section{Differences in respondents' socio-demographic factors}

This study found the socio-demographic characteristics of the respondents were: $51 \%$ aged $21-23$ years, $76 \%$ females, $79 \%$ Chinese, $77 \%$ urban located, $71 \%$ degree students, $36 \%$ pharmacy students and $41 \%$ year 1 study, constituted the majority of the study population. Study population aged 18-26 years were only considered due to their age eligibility for HPV vaccination. Studies targeting the similar age group eligible for HPV vaccination were reported in Malaysia. ${ }^{25}$

\section{Knowledge and awareness status of HPV infection and vaccination}

In general, the respondents' knowledge of HPV infection \& HPV vaccination were poor; the results were comparable with earlier studies. ${ }^{26-28}$ The poor knowledge level may be attributed to the poor importance given for sex education programs in Malaysia. ${ }^{29}$ It is essential that knowledge and awareness of HPV is to be increased so that women will know methods of cervical cancer prevention for them to practice a safer sexual behaviour and male to be concious about the possibility of transmitting the disease to their innocent partners.

\section{HPV vaccination status among unvaccinated}

Among the HPV vaccination status of 18 to 26 years, who were not vaccinated under 2010, national immunization program, Malaysia, almost half (54\%) were vaccinated. It was slightly higher when compared to the reports in US (only $35 \%$ and $44 \%$ ) with at least one dose of the HPV vaccine. ${ }^{30,31}$ About $37 \%$ of them were vaccinated in clinics / hospitals while $7 \%$ were not sure about their place of vaccination, were the population of interest in this study. Nearly $93 \%$ were vaccinated for free either under the $\mathrm{MOH}$ national vaccination program or at the National Population and Family Development Board, Malaysia clinic where government provides free vaccination for unmarried women born between 1990 to 1996 .

\section{Differences in A\&P among socio-demographic characteristics}

The overall attitude \& perception score among socio-demographic characteristics were neutral. Among the age category, more than half $(60 \%)$ of the respondents scored neutral and 32\% scored positive attitude score while the remaining $8 \%$ scored negative. Among the education category, more than half $(60 \%)$, scored neutral, $29 \%$ scored positive while $11 \%$ scored negative attitude. Among the course of study category, $59 \%, 27 \%$ and $14 \%$ scored neutral, positive and negative respectively. Among the year of study, more than half $(60 \%)$ scored neutral and $30 \%$ scored positive whereas, only $8 \%$ scored 
negative A\&P score. Janz and Backer noted that high perceived susceptibility, perceived severity, and perceived benefits may trigger health-promoting behaviours and change people's attitude towards taking health-related actions. ${ }^{32}$ This study was in agreement with a study showed that the intention to get vaccinated increased from $35 \%$ to $69 \%$ after the participants read an information pamphlet on the subject. ${ }^{33}$

\section{Predictor variables which favour HPV vaccination}

Logistic regression was used to evaluate the intention to be vaccinated in association with various socio-demographic variables..$^{34-36}$ The education and year of study were the only variables that were statistically significant. According to the Health Belief Model, a poor knowledge may indicate a lower intention of getting vaccinated against HPV. ${ }^{37}$ This finding explained the low vaccination rate of the respondents in the study. The results of the regression analysis indicate that education and year of study were the only two variables with a significant factor affecting attitudes toward HPV vaccination. These health promotion efforts mainly focused on cervical cancer for preventing HPV infection which may not be related to health of males and genital warts. With a lower level of HPV knowledge, males may be less aware about the potential impact of HPV infection to themselves, and the benefits of vaccination.

\section{Conclusion}

The HPV vaccination status of students in a private University is not high and about half the study population are still to be vaccinated. More aggressive education and promotion activities on HPV vaccination should be organized among age eligible unvaccinated young adults, as their knowledge and attitude towards vaccination is far from acceptable range. Therefore, in addition to providing clear, precise and required information about the implications of HPV infection, addressing misconceptions about HPV infection, its prevention, fears of screening and vaccination is of utmost importance.

\section{Limitations}

In spite of taking adequate care to follow the scientifically valid methods of representative samples, selection bias cannot be ruled out There was no comparison group with which we could have compared our study outcomes. The results may not be representative of the age eligible population as the focus of this study was only among one private university students and many were not approached outside the university campus. However, all attempts were made to minimize such errors through appropriate research design and methodology.

\section{Acknowledgments}

We are grateful to the Management, AIMST University, for granting permission to conduct this study across the various faculties. We would also like to thank the study participants for their time and cooperation extended for this study.

\section{Author contributions}

All authors contributed toward data collection, entry, analysis, drafting and critically revising the paper and agree to be accountable for all aspects of the work.

\section{Conflicts of interest}

The authors declare no conflicts of interest in this work.

\section{References}

1. Hoover DR, Carfioli B, Moench EA. Attitudes of adolescent/young adult women toward human papillomavirus vaccination and clinical trials. Health Care for Women International. 2000;21(5):375-391.

2. Donati S, Giambi C, Declich S, et al. Knowledge, attitude and practice in primary and secondary cervical cancer prevention among young adult Italian women. Vaccine. 2012;30(12):2075-2082.

3. Human Papillomavirus Information Centre. Human Papillomavirus and Related Diseases Report.

4. Laz TH, Rahman M, Berenson AB. Human papillomavirus vaccine uptake among $18 \square$ to $26 \square$ year $\square$ old women in the United States: National Health Interview Survey, 2010. Cancer. 2013;119(7):1386-1392.

5. Makwe CC, Anorlu RI, Odeyemi KA. Human papillomavirus (HPV) infection and vaccines: knowledge, attitude and perception among female students at the University of Lagos, Lagos, Nigeria. Journal of epidemiology and global health. 2012;2(4):199-206.

6. Khor S. [SHARE] Free HPV vaccinations for Malaysian women born in 1990 to 1996.

7. Yacobi E, Tennant C, Ferrante J, et al. University students' knowledge and awareness of HPV. Preventive Medicine. 1999;28(6):535-541.

8. Dell DL, Chen H, Ahmad F, et al. Knowledge about human papillomavirus among adolescents. Obstetrics \& Gynecology. 2000;96(5):653-656.

9. Gerhardt CA, Pong K, Kollar LM, et al. Adolescents' knowledge of human papillomavirus and cervical dysplasia. Journal of Pediatric and Adolescent Gynecology. 2000;13(1):15-20.

10. Raosoft I. Sample size calculator.

11. Cohen J. A coefficient of agreement for nominal scales. Educational and Psychological Measurement. 1960;20(1):37-46.

12. Cohen J. Statistical power analysis for the behavioral sciences. 2nd. 1988

13. AN A, Ping NY, Prajapati SK, et al. Development and Validation of Human Papilloma Virus (HPV) infection and HPV vaccination questionnaire among young adults in Kedah state, Malaysia. Madridge Journal of Pharmaceutical Research. 2017;1(1):33-39.

14. Urrutia MT, Hall R. Beliefs about cervical cancer and Pap test: a new Chilean questionnaire. Journal of Nursing Scholarship. 2013;45(2):126131

15. Chang IJ, Huang R, He W et al. Effect of an educational intervention on HPV knowledge and vaccine attitudes among urban employed women and female undergraduate students in China: a cross-sectional study. BMC Public Health. 2013;13(1):916.

16. Fu LY, Bonhomme LA, Cooper SC et al. Educational interventions to increase HPV vaccination acceptance: a systematic review. Vaccine. 2014;32(17):1901-1920.

17. Henson RK. Understanding internal consistency reliability estimates: A conceptual primer on coefficient alpha. Measurement and Evaluation in Counseling and Development. 2001;34(3):177.

18. Hole G. APA format for statistical notation and other things : Analysis of covariance. Reporting Statistics in APA Style. 2012;1-4.

19. Bhagavathula AS, Bandari DK, Elnour AA, et al. Across sectional study: the knowledge, attitude, perception, misconception and views (KAPMV) of adult family members of people living with human immune virus-HIV acquired immune deficiency syndrome-AIDS (PLWHA). Springerplus. 2015;4(1):1-12.

20. Kaliyaperumal KI. Guideline for conducting a knowledge, attitude and practice (KAP) study. AECS Illumination. 2004;4(1):7-9. 
21. Paradowska D, Tomaszewski KA, Bałajewicz $\square$ Nowak $\mathrm{M}$, et al Validation of the Polish version of the EORTC QLQ $\square$ CX24 module for the assessment of health $\square$ related quality of life in women with cervical cancer. European Journal of Cancer Care. 2014;23(2):214-220.

22. Kahn JA, Xu J, Zimet GD, et al. Risk perceptions after human papillomavirus vaccination in HIV-infected adolescents and young adult women. Journal of Adolescent Health. 2012;50(5):464-470.

23. Miller LA, McIntire SA, Lovler RL. Foundations of psychologica testing: A practical approach. Sage; 2011.

24. George D, Mallery P. SPSS for Windows Step by Step: A simple guide and reference. 2010:18-20

25. Rashwan HH, Saat NZNM, Abd Manan DN. Knowledge, attitude and practice of malaysian medical and pharmacy students towards human papillomavirus vaccination. Asian Pacific Journal Cancer Prevention. 2012;13(5):2279-2283.

26. Khan TM, Buksh MA, Rehman IU, et al. Knowledge, attitudes, and perception towards human papillomavirus among university students in Pakistan. Papillomavirus Research. 2016;2:122-127.

27. Tiro JA, Meissner HI, Kobrin S, et al. What do women in the US know about human papillomavirus and cervical cancer?. Cancer Epidemiology and Prevention Biomarkers. 2007;16(2):288-294.

28. Juntasopeepun P, Suwan N, Phianmongkhol Y, et al. Factors influencing acceptance of human papillomavirus vaccine among young female college students in Thailand. International Journal of Gynecology \& Obstetrics. 2012;118(3):247-250.

29. Mutalip SS, Mohamed R. Sexual education in Malaysia: Accepted or rejected?. Iranian Journal of Public Health. 2012;41(7):34.
30. Schluterman NH, Terplan M, Lydecker AD, et al. Human papillomavirus (HPV) vaccine uptake and completion at an urban hospital. Vaccine. 2011;29(21):3767-3772

31. Licht AS, Murphy JM, Hyland AJ, et al. Is use of the human papillomavirus vaccine among female college students related to human papillomavirus knowledge and risk perception?. Sexually Transmitted Infections. 2010;86(1):74-78.

32. Chiang VC, Wong HT, Yeung PC, et al. Attitude, acceptability and knowledge of HPV vaccination among local university students in Hong Kong. International Journal of Environmental Research and Public Health. 2016;13(5):486.

33. Caskey R, Lindau ST, Alexander GC. Knowledge and early adoption of the HPV vaccine among girls and young women: results of a national survey. Journal of Adolescent Health. 2009;45(5):453-462.

34. Oh JK, Lim MK, Yun EH, et al. Awareness of and attitude towards human papillomavirus infection and vaccination for cervical cancer prevention among adult males and females in Korea: A nationwide interview survey. Vaccine. 2009;28(7):1854-1860.

35. Dunne EF, Unger ER, Sternberg M, et al. Prevalence of HPV infection among females in the United States. JAMA. 2007;297(8):813-819.

36. Chan SS, Ng BH, Lo WK, et al. Adolescent girls' attitudes on human papillomavirus vaccination. Journal of Pediatric and Adolescent Gynecology. 2009;22(2):85-90.

37. Wu CS, Kwong EW, Wong HT, et al. Beliefs and knowledge about vaccination against $\mathrm{AH} 1 \mathrm{~N} 1 \mathrm{pdm} 09$ infection and uptake factors among Chinese parents. International Journal of Environmental Research and Public Health. 2014;11(2):1989-2002. 